\title{
Ciudades emblemáticas del pasado: de la ciudad primigenia (Uruk-Warka) a la megalópolis arquetípica (Teotihuacan)
}

(4inda R. Manzanilla

Universidad Nacional Autónoma de México, México

Fecha de recepción: 25 de julio de 2021. Fecha de aceptación: 18 de agosto de 2021.

Clarisa, ciudad gloriosa, tiene una historia atormentada. Varias veces decayó y volvió a florecer, tomando siempre a la primera Clarisa como modelo inigualable de todo esplendor, por comparación con el cual el estado presente de la ciudad no deja de provocar nuevos suspiros a cada giro de las estrellas.

Italo Calvino (2011: 118).

\section{Resumen}

Este trabajo aborda un tipo particular de asentamiento urbano que fue excepcional en su área, y constituyó un arquetipo en el centro de México; se trata de un asentamiento que experimentó procesos precoces de cambio en lo que V. Gordon Childe denominó "la revolución urbana". Cuando se compara Teotihuacan (durante el periodo Clásico de Mesoamérica, 100-650 d.C.) con los primeros asentamientos urbanos de la Baja Mesopotamia durante el periodo Uruk tardío (3500-3100 a.C.), como Uruk-Warka, las respectivas transformaciones cualitativas que implicaron estos procesos crearon formas innovadoras de vida civilizada, un nuevo tipo de sitio en cada región, y novedosas formas de interacciones sociales y especializaciones en la población urbana. Sin embargo, existen diferencias entre estas dos regiones que deben ser enumeradas. La jerarquía desarrollada de asentamientos con cuatro niveles que es característica de la Baja Mesopotamia no está presente en la cuenca de México durante el periodo Clásico; la retícula urbana ortogonal y la sociedad multiétnica de Teotihuacan son nuevos fenómenos no compartidos por las ciudades tempranas de la Baja Mesopotamia, aun cuando probablemente se presentaron en el valle del río Indo algunos siglos después.

Palabras clave: Baja Mesopotamia, centro de México, multiétnico, ortogonal 


\title{
Emblematic Cities of the Past: From the Primal City (Uruk-Warka) to the Archetypal Megalopolis (Teotihuacan)
}

\begin{abstract}
This paper addresses a particular huge urban settlement which was an exception in its area, and constituted an archetype in Central Mexico, experimenting precocious processes of change in what V. Gordon Childe named "the urban revolution". When comparing Teotihuacan (during the Classic Period of Mesoamerica, 100-650 CE) with the first urban settlements in Lower Mesopotamia during the Late Uruk period (3500-3100 BCE), such as Uruk-Warka, the respective qualitative transformations that these processes entailed created innovative forms of civilized life, a new type of site in each region, and new forms of social interactions and specializations within the urban population. Nevertheless, there are differences between these two regions which should be pointed out. The developed settlement hierarchy with four tiers which is characteristic of Lower Mesopotamia, is not present in Central Mexico; the urban grid and the multiethnic society of Teotihuacan is a new phenomenon not shared by the Lower Mesopotamian early cities, although seen some centuries afterwards in the Indus Valley.
\end{abstract}

Keywords: Lower Mesopotamia, Central Mexico, multiethnic, urban grid

\section{Introducción}

En su célebre obra Le città invisibili, Italo Calvino (2011) retrata diversas ciudades inexistentes, pero que son arquetipos de puertos marítimos, estaciones en el desierto, urbes placenteras, asentamientos conflictivos, ciudades defensivas, es decir, escenarios construidos diversos, con sus respectivas poblaciones que interactúan, se comunican, pelean, crean y destruyen. En sí la ciudad es un producto humano sofisticado y particular, un escenario donde se recrea la complejidad del ser humano, y también uno muy vulnerable a la destrucción.

El concepto de ciudad ha variado a través del tiempo. En primer lugar, muchos coinciden con Sjoberg (1960) en que la ciudad, en contraste con la aldea, es un asentamiento de mayor tamaño, densidad y heterogeneidad, que incluye una amplia variedad de especialistas no vinculados con la producción de alimentos. Sin embargo, como Childe (1957: 37) apuntó, la ciudad es una comunidad que comprende un gran número de gobernantes profesionales, oficiales, sacerdotes, artesanos y personas involucradas en el intercambio de bienes (especialistas de tiempo completo), que no producen alimentos, sino viven de los excedentes aportados por agricultores, criadores de animales, pescadores y cazadores. Hardoy (1964: 20-21) añade que la ciudad es el centro de alguna forma de gobierno, un centro militar, un mercado y un centro de manufacturas; actúa como un polo de innovación tecnológica, de servicios y de intercambio para el área rural que la rodea, como sugirió también Trigger (1972). 
Trigger mismo propuso que las actividades humanas tienden a ser jerarquizadas; a mayor complejidad, las actividades e instituciones sociales son más claramente definidas y el personal que las encabeza, más altamente especializado (Trigger, 1972: 578). El tamaño de las comunidades varía con el número de funciones que llevan a cabo. Obviamente muchas de esas funciones de las ciudades tienen que ver con actividades no-agrícolas (Sanders, 1967: 54).

Siguiendo a Childe (1957), Mumford (1970: 383) establece que el surgimiento de la ciudad como asentamiento nuevo fue posible por una mejora en el cultivo de plantas y en la cría de animales, sobre todo, el cultivo de granos duros que podían ser producidos en abundancia y almacenados; este hecho permitió mantener a diversos especialistas en actividades no relacionadas con la producción de alimentos. Agregaríamos que para Robert McC. Adams (1960: 3-4), la "revolución urbana" fue un proceso social, expresión de cambios en la interacción del hombre con sus congéneres y con el medio ambiente; esta transformación cualitativa descansó sobre los excedentes alimenticios obtenidos de los productores de alimentos. Adams agrega que el elemento esencial del cambio fue la serie de nuevas instituciones que surgieron en dicha transformación, además del aumento en tamaño y en complejidad de la población urbana.

Si bien hay autores como Wheatley (1971: 331) que establecen que la ciudad fue el instrumento que permitió la existencia del Estado, y otros como Trigger (1972: 592) quien piensa que el desarrollo de la ciudad requiere de la expansión de un aparato político tan complejo como el de la ciudad-Estado, en el caso de la Baja Mesopotamia sabemos que el desarrollo de asentamientos urbanos precede la aparición del Estado. Y como veremos más adelante, la economía redistributiva permitió la existencia de comunidades de individuos especializados en diversas tareas, que entregaban excedentes a los templos y otras grandes estructuras tripartitas, a cambio de raciones de alimentos y bienes que no producían (Manzanilla, 1983; 1986; 1997a).

Por último, no quisiéramos pasar por alto las consideraciones de William T. Sanders (1968a: 96-98) en cuanto a los procesos económicos, demográficos y sociales que el urbanismo trajo como resultado; un asentamiento urbano tiene una gran población, con intensa diferenciación interna basada en variaciones de riqueza, especialización económica y poder, concentradas en un área compacta.

La forma, ubicación, funciones, razón de ser y origen de los asentamientos urbanos han sido los factores tomados en cuenta para proponer diferentes tipos de ciudad:

a) Según su ubicación, Mumford (1970: 383-384) propuso ciudades sobre tierra agrícola, a lo largo de fuentes de agua, en puntos estratégicos o en la cercanía de alguna fuente de materia prima.

b) Según sus funciones, Hourani (1970: 9-10) estableció la existencia de ciudades con funciones especiales (aquellas dedicadas al transporte de bienes, como los puertos marítimos, los puertos fluviales o los puertos del desierto, o los centros de peregrinación) y otras ciudades multifuncionales (las que producen y mueven bienes de varios tipos, o bien, los centros de actividades tanto religiosas como seculares [centros de administración, centros provinciales]). 
c) Según su origen, existen ciudades espontáneas, en regiones ricas en recursos, o ciudades creadas (residencias reales, centros de gobierno), como Monte Albán o Menfis. Doxiadis (1968) menciona los asentamientos iniciales que de manera natural se establecen en llanuras, junto al mar o en montañas, y los que, en tiempos de inseguridad, permiten el albergue de poblaciones en retracción.

d) Según su forma, Marcus (1983) establece los modelos morfológicos concéntrico, sectorizado y con múltiples núcleos.

e) Según el tipo de Estado al que están relacionadas, Fox (1977) propone la ciudad real-ritual (de los Estados segmentarios), la ciudad administrativa (correspondiente a los Estados burocráticos), la ciudad mercantil (que se desarrolla en el marco de la ciudad-Estado), la ciudad colonial y la ciudad industrial.

f) Según una combinación de factores arriba expuestos, considero que hay ciudades sin traza regular, que surgen de la agregación de pobladores que migraron de las áreas rurales para convertirse en especialistas urbanos (éstas pueden disponerse en llanuras, valles, o bien, en cerros, y en este último caso, existe una gradación jerárquica según la topografía); otros centros "urbanos" albergan las residencias del rey y su familia, la corte, algunos artesanos, los templos principales y las estructuras administrativas; algunos asentamientos urbanos -los menos- tienen traza ortogonal, generalmente acogen a sociedades multiétnicas muy vinculadas con la producción de manufacturas y el movimiento de bienes. Este último tipo de asentamiento urbano podría estar relacionado con sociedades más bien corporativas (Blanton et al., 1996) y multiétnicas (Manzanilla, 2018a).

Para Mesoamérica en el siglo XVI, Kenneth Hirth (2003: 62) señala que la unidad política fundamental en el centro de México era el altépetl, es decir, una familia real y su territorio, con poblaciones urbanas y rurales. Pone énfasis en que, en el mundo indígena, la dicotomía rural-urbana no existe. Señala que "el tamaño y la estructura de la comunidad urbana era el reflejo de su correspondiente altépetl" (Hirth, 2003: 62).

\section{Algunos apuntes sobre la ciudad primigenia y la "revolución urbana" en la Baja Mesopotamia}

La virtud de la arqueología de Mesopotamia se basa en los numerosos asentamientos excavados por muchos grupos diferentes de arqueólogos multinacionales, y a través de la arquitectura y los materiales asociados podemos detectar procesos de cambio. Desde las fases tempranas de la ocupación neolítica de la Alta Mesopotamia, podemos ver la importancia de los almacenes en el centro de las aldeas, como un indicador de actividades comunales de concentración de alimentos, y su posterior redistribución "circular" (Manzanilla, 1983; 1986), es decir, en el Neolítico, los individuos que aportaron elementos de subsistencia a los almacenes, reciben dichos alimentos a través del circuito redistributivo, quizás mediado por el consejo de mayores. Y la redistribución de bienes fue una constante en los milenios quinto y cuarto antes de nuestra era. 
En varios escritos (Manzanilla, 1983; 1985a; 1986: 261 et seq.; 1992) he expresado mi opinión sobre la importancia de la redistribución asimétrica (circuito de concentración de bienes de subsistencia, y su ulterior destino tanto a los fieles que originalmente aportaron alimentos, como a los especialistas de tiempo completo que no producen alimentos) en el proceso de formación de comunidades de personas en las entidades urbanas tempranas. En Mesopotamia, la concentración de bienes y su redistribución están presentes desde los sitios proto-urbanos Ubaid, pero el clímax se presenta en el periodo Uruk, con la "revolución urbana" de V. Gordon Childe (1973; 1968 [1935]; 1971 [1936]). La secuencia planteada magistralmente por Childe (1964 [1951]: 29-31; 1968 [1935]; 1971 [1936]: 104; 1973: 48) requiere de una agricultura intensiva que permite la producción de un excedente por parte de las comunidades rurales, que posteriormente es entregado en parte a instituciones como el templo. Esta concentración de bienes permite la manutención de especialistas residentes (sacerdotes, burócratas, artesanos especializados, emisarios), el intercambio por materias alóctonas, además de las raciones para los mismos fieles, en lo que he denominado "redistribución asimétrica" (Manzanilla, 1983; 1997a; Espinosa y Manzanilla, 1985; para ejemplos de contextos con almacenamiento centralizado y redistribución, véase Palmieri, 1973).

Para el caso de Mesopotamia, Frank Hole (1974) estableció un punto más: la desigual distribución de recursos a escala macro-regional estimuló la especialización de distintos tipos de productores de alimentos; este hecho provocó el surgimiento de organizaciones que controlasen la redistribución, y así se estimuló la diversificación de la dieta. En una misma línea de pensamiento, William Sanders (1968b) habló de economía simbiótica para el Formativo del centro de México; la especialización intercomunal de los asentamientos formativos de la cuenca de México requirió de un sitio donde se diera la redistribución de los bienes producidos de manera especializada por cada aldea, y la obtención de bienes diversificados a través del circuito redistributivo.

Los desarrollos tecnológicos concomitantes a la "revolución urbana" del periodo Uruk tardío (la rueda, el torno de alfarero, la tecnología del bronce, el arado, la escritura, y la continuación del sellado de bienes como medio contable) se dieron gracias a una economía redistributiva centrada en los grandes edificios tripartitos, como los que podemos ver en Uruk-Warka, ya que con los bienes almacenados se podía mantener a estos especialistas (Manzanilla, 1986). Estos eventos promovieron estructuras corporativas complejas, que Susan Pollock denominó "oikoi" (Pollock, 1999: 118), con individuos que aportaban mano de obra y productos al sistema redistributivo. Y, como señala Frangipane (2001: 416), lo que era administrado en Mesopotamia era la distribución de bienes de subsistencia (raciones de comida o comensalismo).

En Mesopotamia, las ciudades aparecen en el periodo Uruk tardío (hacia 35003100 a.C.), y según mi opinión, poco antes de la aparición del Estado, que podemos ver plenamente establecido con la presencia de palacios y de ciudadesEstado sumerias del periodo Dinástico Temprano (hacia 2900-2340 a.C.). Sin embargo, otros autores (por ejemplo: Stein y Özbal, 2007: 339, 341) establecen sociedades estatales desde el periodo Uruk. En este proceso precoz de desarrollo de asentamientos urbanos destaca la ciudad primigenia: Uruk-Warka. Hacia 
3400 a.C., Uruk tenía $2,5 \mathrm{~km}^{2}$ de extensión, y aumentó a $5 \mathrm{~km}^{2}$ a principios del III milenio a.C. (Nissen, 2018: 61-62). Como bien dice Nissen, la ciudad de Uruk no fue capital supra-regional, ni tuvo una función especial, como sí sucedió con Nippur (Gibson, 1993), que fue asiento de la deidad Enlil, dios supremo, y sede de la asamblea de los dioses.

Uruk-Warka fue la ciudad de un territorio agrícola y ganadero, con asentamientos aldeanos en un cinturón concéntrico a $12 \mathrm{~km}$ de la ciudad (Nissen, 2018: 62), aproximadamente 112 aldeas y 10 villas alrededor del centro urbano (Adams y Nissen, 1972). El crecimiento demográfico es patente en la fundación de muchos nuevos sitios construidos sobre suelo estéril (Adams, 1972: 61-62); sin embargo, en la ciudad de Uruk, el proceso fue explosivamente rápido y acompañado de cambios estructurales profundos, con la construcción de varios conjuntos arquitectónicos monumentales, muchos de ellos de carácter ceremonial (los templos tripartitos, sede de los circuitos redistributivos). La urbanización de la Baja Mesopotamia implicó una redistribución de la población sedentaria, ya que varios sitios rurales fueron abandonados, y sus pobladores fueron a vivir a los centros urbanos (Manzanilla, 1986: 121).

Una de las características concomitantes del desarrollo de entidades urbanas en el periodo Uruk fue la exportación de los módulos hacia regiones ricas en recursos, estableciendo colonias extractivas y de intercambio (Stein y Özbal, 2007: 339).

\section{La gran megalópolis multiétnica de Teotihuacan}

El surgimiento de la gran urbe de Teotihuacan durante el periodo Clásico representa la llegada de un nuevo tipo de asentamiento: una metrópolis de 20 $\mathrm{km}^{2}$, una de las grandes urbes del mundo antiguo. Si tomamos en cuenta los diversos tipos de ciudades enunciados en la introducción, Teotihuacan fue una ciudad construida en el fondo de un valle, sobre tierra agrícola (Fig. 1); con carácter multifuncional y origen espontáneo; en una región rica en recursos para la construcción (escoria volcánica, toba, basalto, andesita); presencia de manantiales de agua, y cercanía a fuentes de obsidiana, material que constituyó la base de la tecnología lítica. Fue un asentamiento urbano multicéntrico, con traza regular ortogonal, con una sociedad multiétnica y corporativa en la base y en la cima, y varias de estas características la hacen una ciudad excepcional (Manzanilla, 2009; 2015; 2017a). Constituyó la capital de un Estado de primera generación que he denominado "tipo pulpo" (Manzanilla, 2017a), que a mi parecer fue débil y que se basó en un pacto con los diversos grupos étnicos de la ciudad, y en las alianzas fraguadas por cada uno de los 22 barrios de la ciudad con diversos sectores de Mesoamérica.

Cuando uno llegaba a Teotihuacan, no podía sino maravillarse de la brillantez de sus colores (De la Fuente, 1996). También maravillaba la traza tan regular de Teotihuacan (Millon, 1973). Era la primera vez que se veía este fenómeno singular en el centro de México; este modelo de gran ciudad con un orden dictado por la cosmogonía (el espacio terrestre dividido a los cuatro rumbos del universo), simbolizará la gran Tollan arquetípica (Manzanilla, 1997b), la "gran ciudad". 


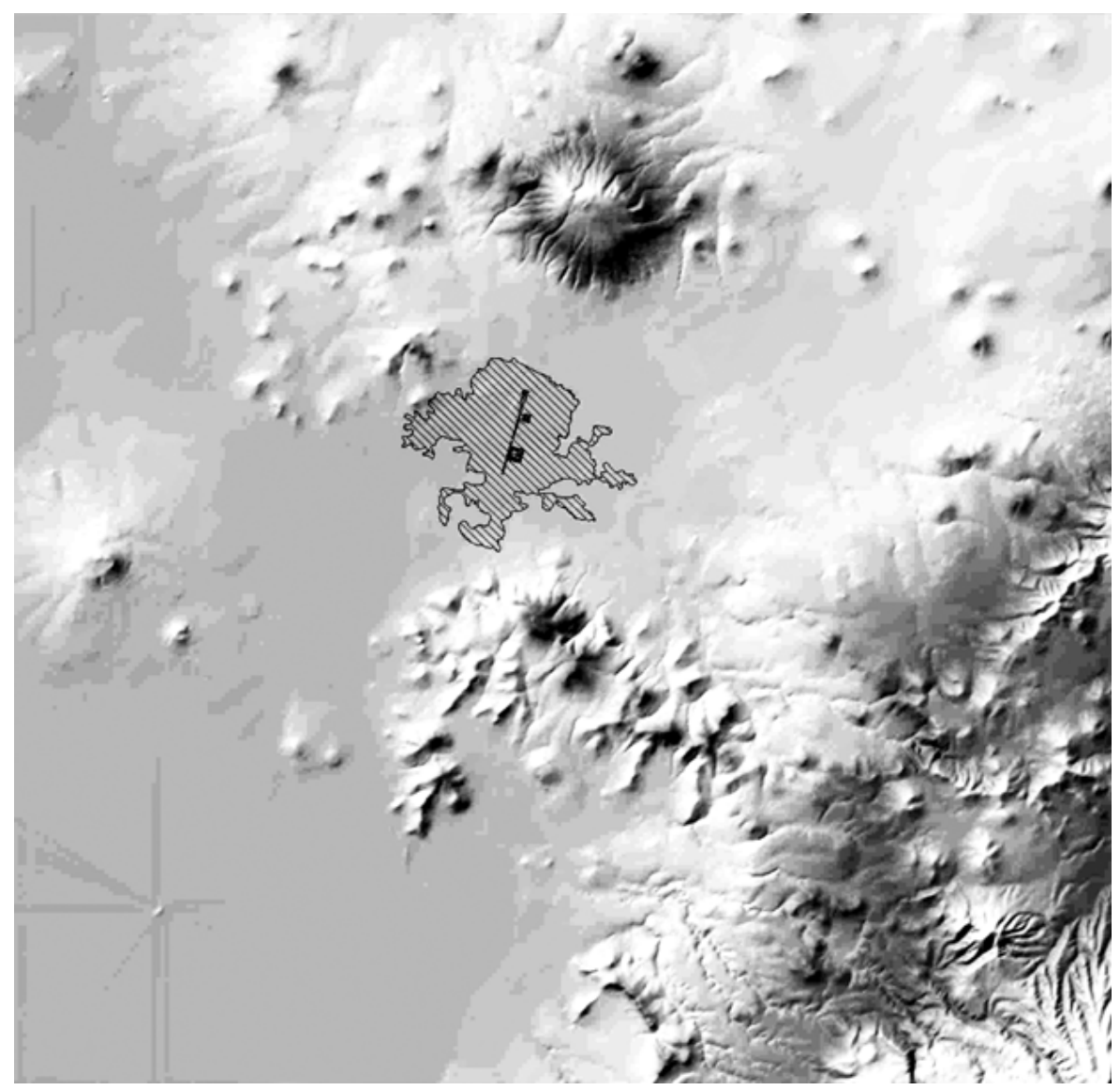

Fig. 1. Mancha urbana de Teotihuacan (mapa de Gerardo Jiménez para mi proyecto).

La gran Calzada de los Muertos, su eje norte-sur, culmina en la majestuosa Plaza de la Luna; uno observa desde lejos la Pirámide de la Luna protegida por el cerro Gordo (un gran estrato-volcán extinto, la "montaña sagrada", la Tenan ["nuestra madre"] del siglo XVI), que es el marco escénico de la pirámide. Cuando se camina la Calzada de los Muertos de sur a norte, la Pirámide de la Luna crece visualmente hasta cubrir todo el horizonte. Si uno ve la Pirámide del Sol desde la Plaza de la Luna, teniendo como trasfondo el cerro de Patlachique, uno observa que el perfil de la pirámide hace "eco" de la silueta del cerro al sur (Fig. 2), ni más ni menos que los ángulos de reposo de los materiales inertes. $\mathrm{Y}$ es que en Teotihuacan existe armonía entre lo natural y lo construido.

Ubicada en el fondo de un valle de origen volcánico, en la porción semiárida de la cuenca de México, tenía acceso directo al sistema lacustre por el lago de Texcoco, ubicado inmediatamente al sur. La cuenca misma era una región volcánica con lagos, planicies lacustres, somontes y sierras muy ricas en recursos variados (Wolf, 1976; Sanders et al., 1979), tanto que Sanders (1968b) propuso una economía simbiótica desde el Formativo. 


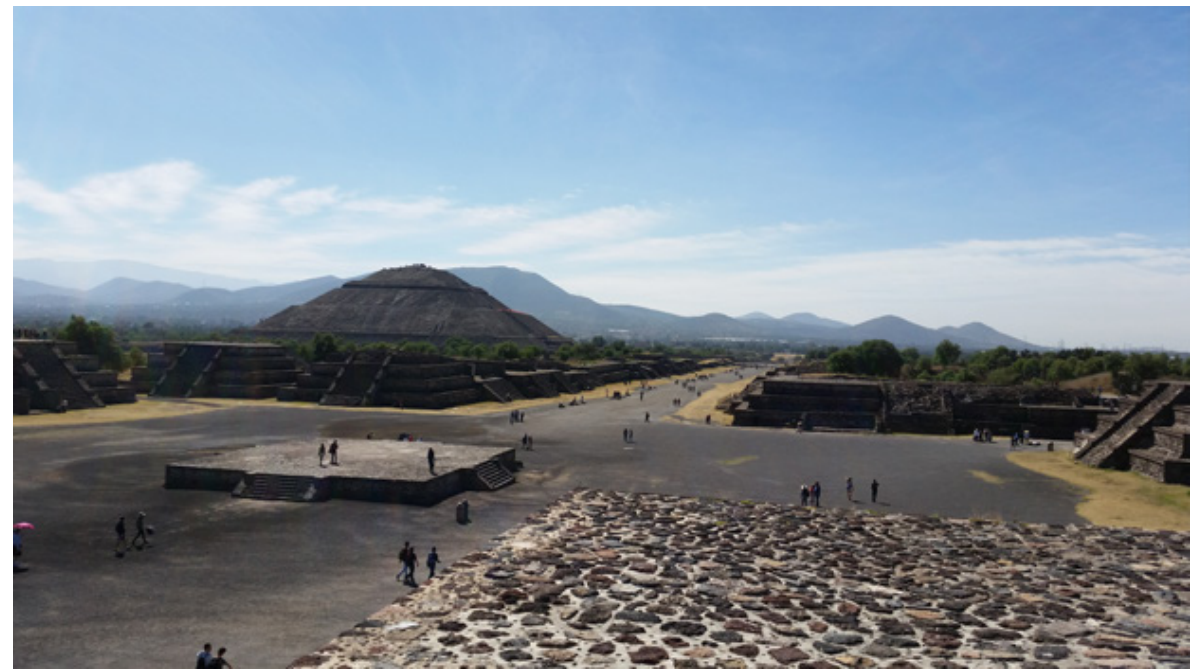

Fig. 2. Vista de Teotihuacan desde la Plaza de la Luna hacia el sur (foto tomada por Linda R. Manzanilla).

\section{El origen de esta gran ciudad}

Los asentamientos previos al surgimiento del asentamiento urbano de Teotihuacan son aldeas, como Cuanalan (Manzanilla, 1985b), con un sistema de abasto de amplio espectro, que incluyó cuatro variedades de maíz (choclo), tres variedades de frijol (pallares), amaranto, setaria, tomate silvestre, cebollita silvestre, cactos y frutos como el tejocote (Crataegus mexicana); en cuanto a la fauna, atestiguamos la cría de guajolote y perro, así como la caza de venado cola blanca y dos especies de conejo, la pesca de agua dulce y el aprovechamiento de ranas y tortugas (Manzanilla, 1985b). Esta aldea del Formativo tardío (400-80 a.C.) tenía chozas de bajareque de circa $25 \mathrm{~m}^{2}$, dispuestas alrededor de patios empedrados, como sucede en muchos sitios formativos de Mesoamérica.

Uno de los factores que aceleraron los cambios que se vivieron en el valle de Teotihuacan a principios de nuestra era fue la llegada de gente de la región de Puebla y probablemente también de Tlaxcala, que huyó de la gran erupción del volcán Popocatépetl hacia 80 d.C. (Plunket y Uruñuela, 1998). Los sitios abandonados a raíz de la erupción, ubicados en la ladera oriental del volcán, presentan una conformación más compleja que las aldeas del valle de Teotihuacan; en ellos se encuentran múltiples conjuntos de tres estructuras alrededor de un patio con altar, con arquitectura de tablero-talud, elementos que fueron recreados de manera monumental en la futura ciudad de Teotihuacan.

Lo que observamos en los primeros dos siglos de la nuestra era en el valle de Teotihuacan es la fundación de varios conjuntos de construcciones y la edificación de las grandes pirámides; grupos procedentes de otras regiones de Mesoamérica llegaron a un valle que requería de mano de obra para la labor de edificar múltiples complejos arquitectónicos. Sin embargo, es hacia 150200 d.C. que se trazan los ejes de la ciudad y comienza la construcción del primer enorme asentamiento ortogonal de la fase Tlamimilolpa (200-350 d.C.) (Millon, 1973), con una orientación de $15^{\circ} 17^{\prime}$ azimuth. Se edifican conjuntos 
multifamiliares de departamentos que albergan a los grupos corporativos de la ciudad (Manzanilla, 1996; Manzanilla, 1993), y que es una de las características excepcionales de Teotihuacan que no hallamos en otros sitios contemporáneos. Fue la solución para dar orden a la diversidad. Estos conjuntos habitacionales se disponían alrededor de centros de barrio como Teopancazco (Manzanilla, 2006a; 2009; 2012a; 2012b), probablemente 22 en la gran urbe (Froese et al., 2014). Además, observamos "barrios étnicos" en la periferia (Manzanilla, 2012c) y las construcciones administrativas y rituales de la élite gobernante a lo largo de la Calzada de los Muertos.

La ubicación de la ciudad de Teotihuacan fue elegida tomando en cuenta varios factores: por un lado, la presencia de varios tipos de materiales volcánicos para la construcción de la futura gran ciudad y la cercanía a las minas de obsidiana de Otumba y Pachuca; por el otro, la existencia de manantiales y tierra aluvial al sur; la posición del valle en la ruta más accesible de tránsito desde el golfo hacia la cuenca de México, y por último, la cercanía al lago de Texcoco (Millon, 1973).

\section{La traza urbana}

Muy pocos asentamientos urbanos de Mesoamérica tienen traza ortogonal. Teotihuacan fue el primero de este tipo, y Tenochtitlan del siglo XV-XVI, el último. La ciudad de Teotihuacan fue planificada siguiendo una retícula de calles paralelas y perpendiculares, orientada a $15^{\circ} 17^{\prime}$ al este del norte. La Calzada de los Muertos es el principal eje norte-sur; una posible Avenida EsteOeste (véase Millon, 1973) podría, junto con la primera, dividir la ciudad en cuatro distritos, de donde propongo emergían los cuatro co-gobernantes de la capital (Fig. 3) (Manzanilla, 2009; 2017a); y esta división en cuatro emula la flor de cuatro pétalos, posible glifo emblema de Teotihuacan (López-Austin, 1989).

Además de grandes depósitos de agua ubicados al noroeste de la Pirámide de la Luna, la ciudad contaba con una extensa red de drenaje subterráneo construida con lajas de andesita y basalto muy bien labradas. El cauce del río San Juan fue canalizado y su curso fue modificado con el fin de que se ajustase a la traza de la ciudad, de ahí que pase perpendicular a la Calzada de los Muertos, al norte de la Ciudadela. Además, hay pozos para la obtención de agua en varios puntos de la ciudad. En el sector suroeste del valle de Teotihuacan se concentraron originalmente varios manantiales, y se estableció un sistema de "chinampa seca" en dicha región (Lorenzo, 1968), es decir, parcelas de cultivo circundadas por canales de agua. Asimismo, tenemos evidencias de que la mancha urbana del sector meridional tapó varios sistemas primigenios de canalización de agua (Gazzola, 2017).

A lo largo de la Calzada de los Muertos se disponen edificios públicos administrativos y ceremoniales. Las dos plazas de congregación más importantes se hallaban al norte (la Plaza de la Luna) y al centro (La Ciudadela), pero soy de la opinión que a estas grandes plazas acudían solamente los nobles que, en 
estructuras corporativas, eran miles de personas. La gente del común estaba adscrita a un barrio, y permanecía allí. Frente a La Ciudadela se encuentra un espacio abierto rodeado por dos alas al norte y al sur, denominado el Gran Conjunto. Millon (1973) propuso que fue el mercado más grande de la ciudad, ya que se encuentra en la parte central del asentamiento urbano; sin embargo, no hay indicadores concretos que apoyen esta hipótesis, y sería muy anómalo tener un gran mercado (tipo Tlatelolco de los mexicas) en una ciudad de primera generación.

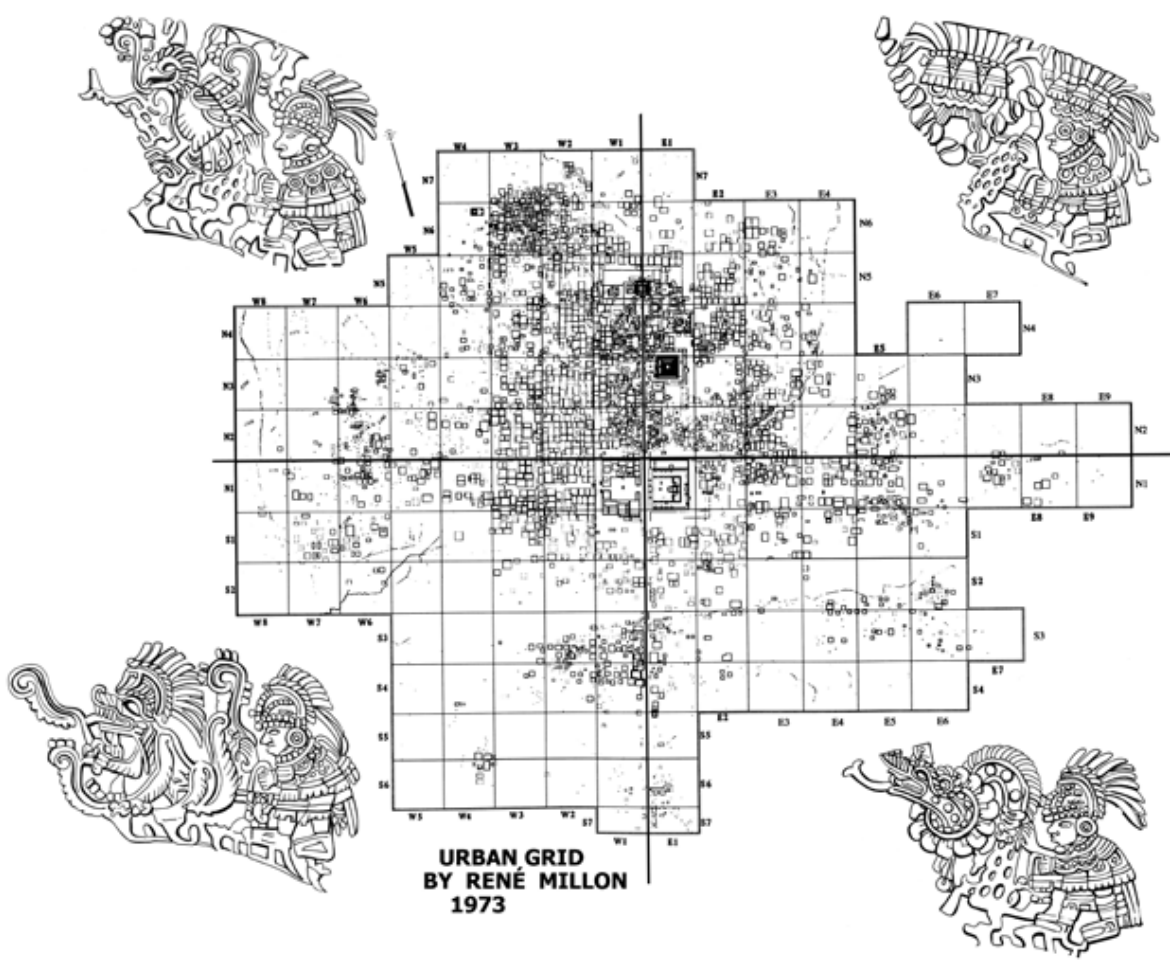

Fig. 3. La ciudad de Teotihuacan y sus posibles distritos (propuesta de Linda R. Manzanilla [2009]; dibujo de Rubén Gómez, César Fernández y Linda R. Manzanilla).

Alrededor del área central que circunda la Calzada de los Muertos, se disponen varios complejos residenciales teotihuacanos de diversas jerarquías, entre los cuales se pueden citar: Atetelco, Yayahuala, Tetitla, Tlamimilolpa, Xolalpan (Séjourné, 1959; 1966; Linné, 1934; 1943; Manzanilla, 1996). Estos complejos de varios cuartos son una característica teotihuacana notable, ya que varias familias no necesariamente emparentadas entre sí compartían el espacio doméstico en un conjunto de departamentos (Manzanilla, 1996; Manzanilla, 1993), así como actividades u oficios, constituyendo grupos corporativos. Estos complejos estaban separados de la vida del exterior por altas murallas sin ventanas.

Gracias al proyecto interdisciplinario (véase Manzanilla, 2007b) que encabecé de 1985 a 1988 en uno de estos conjuntos de departamentos ubicado en la periferia noroeste de la ciudad, en Oztoyahualco 15B (Manzanilla, 1993; Manzanilla, 1996) (Fig. 4), sabemos que tres familias de albañiles de estuco tuvieron sus apartamentos en el conjunto. Cada familia tenía una cocina, un 
almacén, pórticos para trabajar, dormitorios, traspatios para actividades sucias (como la cría de animales domésticos como el perro, el guajolote, y en este conjunto en particular, el conejo; el destazamiento de animales y otras actividades), patios de servicio y patios rituales. Cada familia tuvo una deidad patrona distinta (Manzanilla, 1996). Por lo tanto, se trata de familias independientes que viven en un mismo conjunto debido al hecho de que comparten una actividad u oficio, es decir, grupos corporativos.

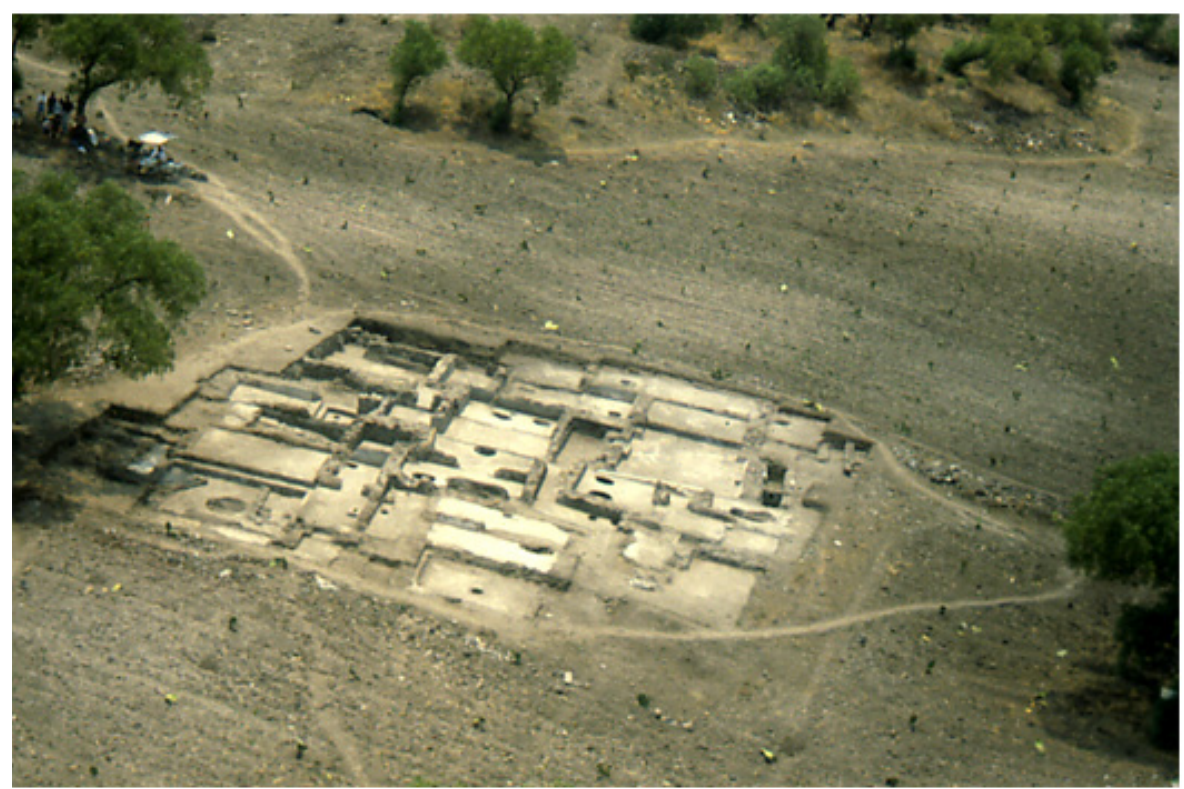

Fig. 4. Conjunto multifamiliar de estatus bajo ubicado en Oztoyahualco 15B, periferia noroeste de Teotihuacan, excavado por Linda R. Manzanilla de 1985 a 1988 (foto de Linda R. Manzanilla).

Los conjuntos de departamentos de los grupos corporativos se dispusieron alrededor de los cerca de 22 centros de barrio (Froese et al., 2014), en los que se coordinaban las actividades de cada barrio. Según nuestro modelo derivado de las excavaciones extensivas de Teopancazco de 1997 a 2005 (Fig. 5), en estos centros se concentraba la actividad de artesanos adscritos al barrio, muchos de los cuales provenían de otras regiones de Mesoamérica (Manzanilla, 2006a; 2009; 2012a; 2017d; 2018a; 2018b; 2020). La gente del común adscrita a un barrio específico acudía a hacer ritual en su centro de barrio (Fig. 6); trabajaba para el barrio en la construcción, la elaboración de manufacturas y el movimiento de bienes; se abastecía de alimentos por medio del trueque en el tianguis (mercado informal) del barrio.

Tanto los barrios foráneos de la periferia de Teotihuacan, como los barrios multiétnicos del anillo interior, se encuentran dispuestos en cuatro distritos (véase la Fig. 3), probablemente unidades administrativas y de co-gobierno (Manzanilla, 2009; 2017a). 


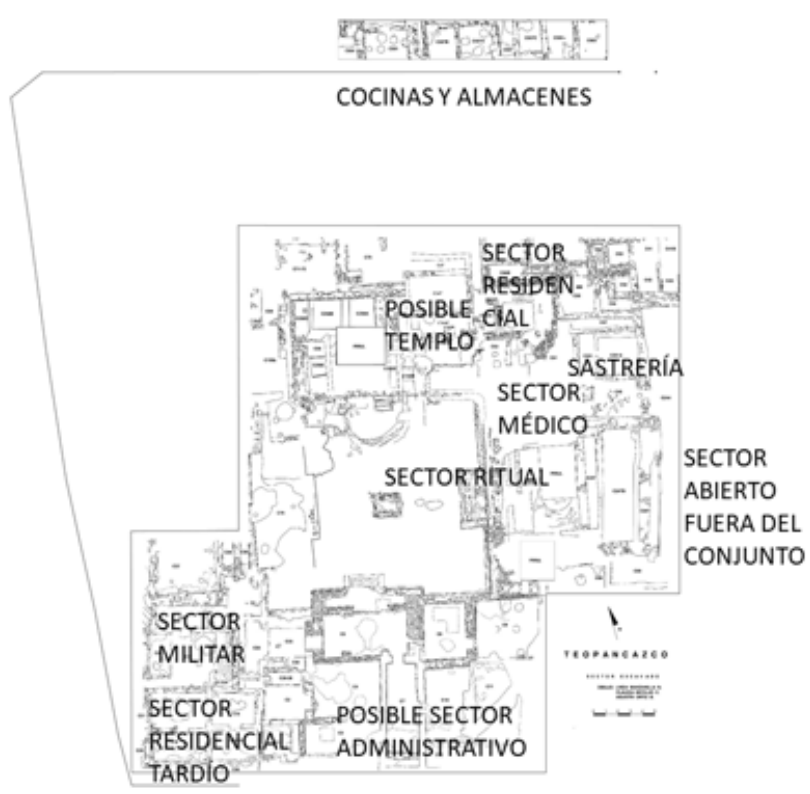

Fig. 5. Los sectores funcionales de Teopancazco, según excavaciones de Linda R. Manzanilla de 1997 a 2005 (dibujo de Linda R. Manzanilla y Rubén Gómez).

\section{El sistema de abasto}

Otro elemento de excepcionalidad de Teotihuacan respecto de otros casos de desarrollos urbanos, es el hecho de que la gran ciudad de $20 \mathrm{~km}^{2}$ está rodeada de sitios rurales de la cuenca de México; no se cuenta con una jerarquía de asentamientos de varios niveles, como sucede en otros casos prístinos de urbanización. El único centro secundario pudo haber sido Azcapotzalco. Teotihuacan concentró del 50 al $60 \%$ de la población de la cuenca; el resto de los sitios parecen ser asentamientos rurales (villorrios y diversos tipos de aldeas; véase Sanders et al., 1979) y algunos pequeños centros de concentración de bienes de subsistencia.

Propongo que había dos circuitos de abasto de bienes: 1. los bienes de subsistencia fluían a través del tianguis (mercados periódicos de barrio) en espacios abiertos anexos a los centros de barrio; 2 . los bienes foráneos, exóticos y suntuarios llegaban a la población urbana por medio de las caravanas organizadas por la élite intermedia de cada barrio, a través de corredores de sitios aliados (García Cook, 1981), es decir, llegaban al centro de barrio (Manzanilla, 2011a; 2011b; 2012a; 2015; 2017b; 2018b). Además, las élites gobernantes organizaron expediciones para abastecerse de bienes suntuarios muy preciados, procedentes de regiones muy distantes, como la mica proveniente de la región de Ejutla en Oaxaca (Manzanilla et al., 2017; Rosales de la Rosa y Manzanilla, 2011).

Para el periodo Clásico, podemos decir que los pobladores de Teotihuacan comían maíz, amaranto, frijol (tanto vulgar como ayocote), calabazas (hasta cuatro variedades), chiles, quenopodiáceas, quelites, verdolaga, tomate, cactos (tuna, biznagas), tejocote y capulín (McClung, 1979; Manzanilla, 1996). En 
viviendas multifamiliares como Oztoyahualco 15B también hallamos plantas medicinales como Casimiroa edulis. Asimismo, se consumieron animales domésticos, como el perro, el guajolote y el conejo de cría, además de aquellos provenientes de la caza, como el venado cola blanca y la liebre; las aves acuáticas atrapadas en el sistema lacustre; otros animales acuáticos, como las tortugas terrestres y los peces de agua dulce (Manzanilla, 1993; Manzanilla, 1996; Starbuck, 1975; Valadez, 1993). Sin embargo, en los centros de coordinación de los barrios, como fue el caso de Teopancazco (Manzanilla, 2006a; 2009; 2015; Manzanilla, 2012d; 2017d; 2017e; 2018b; 2020), gracias al sistema de caravanas que cada barrio organizaba hacia distintas regiones de Mesoamérica, se tenía acceso a fauna y flora alóctona (Manzanilla, 2011a; 2015; 2017a; 2017b). Para Teopancazco obtuvimos 14 variedades de peces de las lagunas costeras de Veracruz, particularmente del área de Naulta, cangrejos, cocodrilo, tortugas (Rodríguez Galicia y Valadez Azúa, 2013), y mantas de algodón para vestir a la élite intermedia, como lo muestra el famoso mural hallado en el sitio (véase Fig. 6).

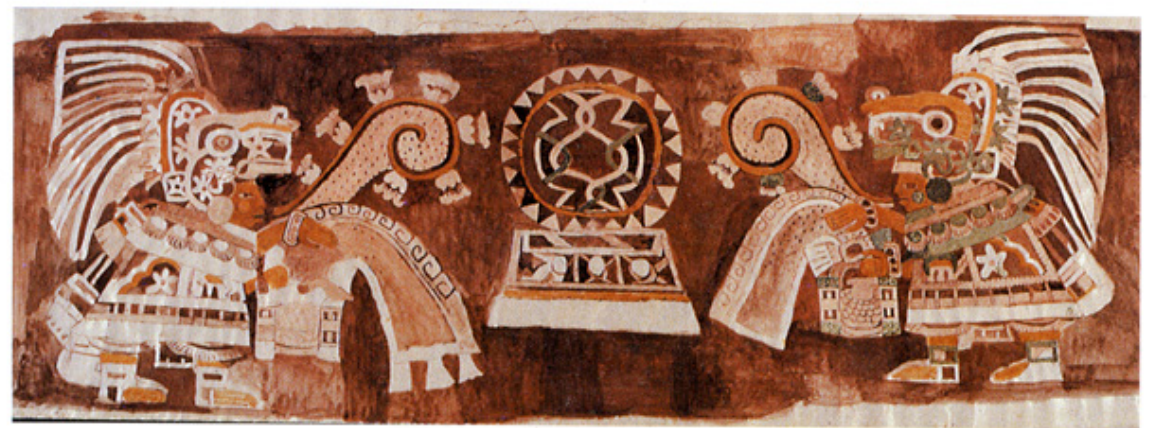

Fig. 6. Mural principal de Teopancazco. Archivo del proyecto "La pintura mural prehispánica en México". Instituto de Investigaciones Estéticas de la UNAM. (Dibujo de Adela Bréton).

Por lo tanto, tenemos por lo menos dos circuitos de movimiento de alimentos: el que atañe a las plantas y animales de la cuenca de México y sector oriental del valle de Toluca, y que dependía de que cada barrio organizara un mercado informal cada $\mathrm{X}$ días para intercambiar por trueque los productos urbanos por aquellos rurales, y por otro lado, las caravanas de cada barrio que transitaban por corredores de sitios aliados hacia puntos diversos de Mesoamérica, y que permitían que la población urbana accediese a bienes foráneos y suntuarios (Manzanilla, 2011a; 2015; 2017a).

Se ha pensado que los valles de Toluca, Hidalgo, Puebla-Tlaxcala y porción oriental de Morelos formaban parte del área inmediata de captación de Teotihuacan (Manzanilla, 2001). Teotihuacan organizó enclaves directamente relacionados con materias primas estratégicas para el Estado en Chingú, Hidalgo (para aprovisionarse de la cal), la sierra de las Navajas (para la obsidiana), y posiblemente Azcapotzaltongo, en la porción oriental del valle de Toluca (para recursos alimenticios). Sin embargo, cada barrio de Teotihuacan fraguó alianzas hacia diversas regiones de Mesoamérica, y por lo tanto, una gran diversidad de materias primas y productos elaborados de carácter alóctono llegaron a la ciudad. 


\section{La población teotihuacana y su carácter multiétnico}

La afluencia de trabajadores foráneos a la ciudad se debió a la necesidad de mano de obra para la construcción, la producción de manufacturas y el movimiento de bienes. Después de la migración de gente huyendo de la erupción del volcán Popocatépetl (a un valle ya ocupado por aldeas formativas como Cuanalan), pronto se presentó la llegada de migrantes de Oaxaca, PueblaTlaxcala y Veracruz. Más tarde tendremos también la llegada de gente de Michoacán.

En la periferia de la ciudad yacían los barrios étnicos (Manzanilla, 2012c: 57): el Barrio Oaxaqueño ocupaba, al parecer, toda la Calzada Oeste de la ciudad, en tres concentraciones (Ortega Cabrera, 2014; Spence, 1992), y constituía la minoría más grande de Teotihuacan. El Barrio de los Comerciantes (Rattray, 1988; 1989) estaba ubicado al este, y se trataba de comerciantes veracruzanos procedentes de dos regiones de la costa del golfo de México (Price et al., 2000). En la Estructura 19 de El Cuartel se estudió a un pequeño grupo de michoacanos (Gómez Chávez, 1998) que convivía con oaxaqueños.

El segundo anillo estaba en la parte central de la ciudad, y abarcaba la mayor parte de los 22 barrios (Froese et al., 2014), cada uno con su centro de coordinación, sus administradores (nobles de rango medio), sus intereses y alianzas en sitios de cada corredor, y su posible estructura de "sociedad de casa" (Manzanilla, 2007a; 2011a; 2015).

Además de los oaxaqueños, michoacanos y veracruzanos señalados en los "barrios étnicos", suponemos que también había poblanos, tlaxcaltecas, hidalguenses y guerrerenses que traían diversos bienes a la ciudad. Aunque no como barrio formal todavía, también se ha detectado la presencia de pintura mural y textos mayas en Tetitla (Taube, 2003) y recientemente en la Plaza de las Columnas (Sugiyama et al., 2016).

El sistema de caravanas organizado por cada barrio de la gran ciudad hacia sitios proveedores de materias primas y bienes suntuarios (Manzanilla, 2011a) permitió la afluencia de artesanos multiespecializados, que serían anclados en el centro de barrio, administrado por la élite intermedia de Teotihuacan, como lo demostró el caso de Teopancazco, al sur de La Ciudadela (Manzanilla, 2012d; 2017d; 2018b; 2020). Estos migrantes murieron en Teotihuacan, pues hemos hallado sus entierros. En sus actividades para el barrio, trabajaron largas horas en posiciones acuclilladas o incómodas, tanto que dejaron huellas entesopáticas en sus esqueletos. Individuamos a quienes hacían los atuendos y tocados complejos de la élite intermedia que administraba el barrio, visibles en el famoso mural de Teopancazco (véase la Fig. 6); otros ablandaron fibras con los dientes, o elaboraron cestos y redes; algunos pintaron cerámica o murales; ciertos individuos tienen huellas de haber lanzado las redes para atrapar los peces en las lagunas costeras, que posteriormente fueron traídos a Teopancazco abiertos como mariposa; otros más cargaron pesos con mecapal en la espalda, y caminaron largas distancias por los corredores de sitios aliados; hubo buzos que probablemente trajeron la gran variedad de 
moluscos marinos al centro de barrio. Muchos tuvieron estrés nutricional en su infancia, y es de esperar que hayan migrado a la ciudad para tener mejores condiciones de vida, entre las cuales se cuenta el tener raciones de comida diarias para asegurar su sustento y permitirles una dedicación de tiempo completo (Manzanilla, 2011a; 2012d; 2015; 2017d; 2018b; 2020; Rodríguez Galicia y Valadez Azúa, 2013).

Varios de los individuos decapitados (ca.65\%) de Teopancazco en un ritual de terminación de la fase Tlamimilolpa tardía, en 350 d.C., son migrantes, emulando un ritual parecido, presente en Cerro de las Mesas, Veracruz (Drucker, 1943), en el Formativo.

Como se observó en los estudios de isótopos estables y de estroncio ${ }^{87 / 86}$, así como en el estudio del ADN mitocondrial, el centro de barrio multiétnico de Teopancazco que estudié de 1997 a 2005 tuvo una población muy heterogénea cultural y biológicamente (Manzanilla, 2015; Manzanilla, 2017d; 2020; ÁlvarezSandoval et al., 2015). Es muy probable que la mayoría de los centros de barrio de Teotihuacan tuviesen artesanos foráneos adscritos para labores muy especializadas de manufactura; a través de caravanas que transitaban por sitios aliados, producto de vínculos particulares de cada barrio, no sólo se traían materias primas y bienes foráneos, sino que se convocaba a trabajadores especializados para llegar a la gran ciudad y quedar como artesanos dependientes del barrio en particular (Manzanilla, 2015; 2017d; 2020).

\section{La especialización del trabajo}

Las manufacturas teotihuacanas gozaron de prestigio en Mesoamérica. Se ha calculado que un porcentaje importante de la población se dedicaba a las tareas artesanales. Según mi propuesta, existen cuatro escalas relativas a la producción artesanal en la gran ciudad (Manzanilla, 2006b; 2017a): algunos objetos se producían en los conjuntos de departamentos para satisfacer las necesidades cotidianas de los grupos corporativos; muchos eran producidos en la periferia de la ciudad, e involucraban objetos utilizados por la población urbana. Por otro lado, están los artesanos adscritos y dependientes de las élites intermedias que administraban los centros de barrio o de las élites gobernantes de los conjuntos palaciegos.

Dentro de las labores artesanales, destacan los talladores de obsidiana, cuyos talleres llegaron a una especialización a nivel del tipo de artefacto que producían. Muchos de ellos se ubicaban en torno a la Pirámide de la Luna (Carballo, 2011), para la elaboración de puntas de dardo y excéntricos. Sin embargo, muchos talleres se dispusieron en la porción nororiental de la ciudad, es decir, el primer lugar que los que venían de los yacimientos de obsidiana tocaban al llegar a la metrópolis.

Por otro lado, los talleres de los alfareros se disponían tanto en el sector noroeste como en el sureste. Las vajillas utilitarias, como la Anaranjada San Martín, se hacían en talleres como el de Tlajinga, en la periferia sureste (Storey y Widmer, 
1989). También se ha excavado un taller vigilado por las élites, dedicado a la elaboración en serie de placas y adornos para incensarios que intervenían en el ceremonial teotihuacano (Múnera, 1985).

En sitios como Tecópac se han encontrado evidencias de trabajo de lapidaria menor para la población urbana (Turner, 1992). Sin embargo, en centros de barrio, como La Ventilla 92-94, existen indicios de zonas de manufactura muy especializada de objetos de concha y lapidaria mayor (Gazzola, 2005). Asimismo, hay talleres que involucran materias primas suntuarias, como la mica (procedente de Oaxaca), en complejos palaciegos como Xalla (Fig. 7), al norte de la Pirámide del Sol (Manzanilla et al., 2017; Rosales de la Rosa y Manzanilla, 2011), directamente relacionados con las élites gobernantes.

Por otro lado, existían especialistas en la construcción y acabado de los edificios, así como en la preparación de mezclas y pigmentos (Manzanilla, 1993; López-Puértolas et al., 2020).

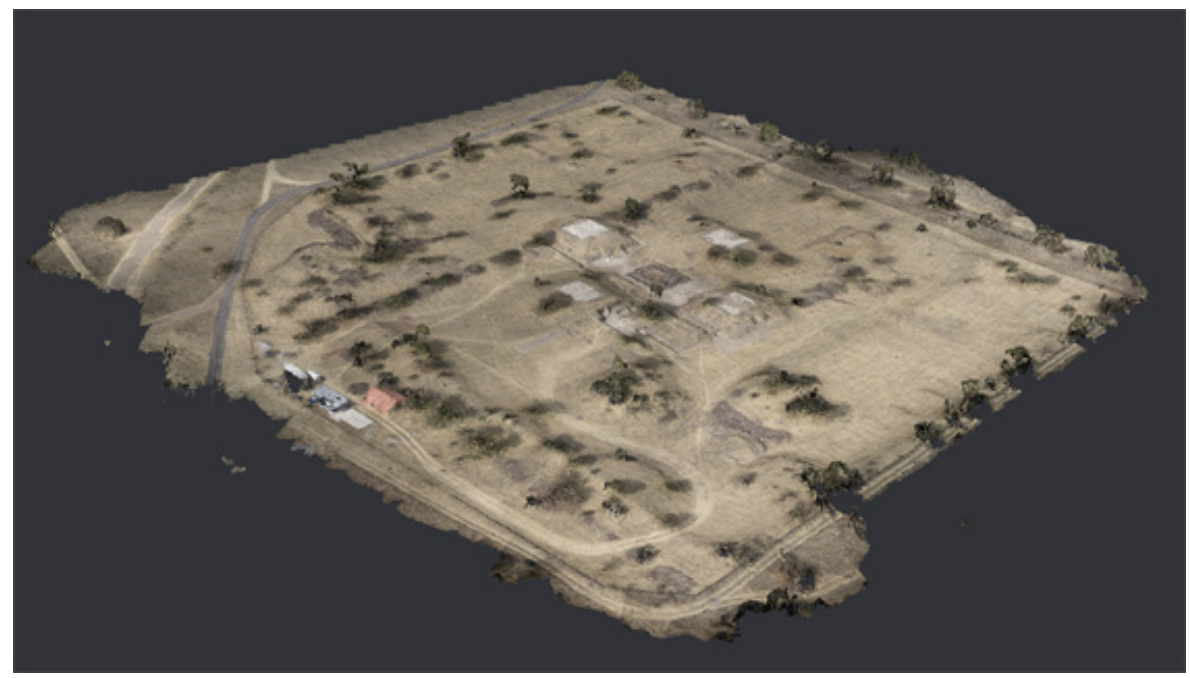

Fig. 7. Complejo palaciego de Xalla, excavado por Linda R. Manzanilla (2000-2020) (imagen generada con dron por Geneviève Lucet y su equipo para mi proyecto).

\section{La organización social y política}

Existen dos posiciones encontradas sobre la organización política de Teotihuacan: quienes sostienen que estuvo regida por un gobernante único y otros quienes hemos propuesto un co-gobierno (Paulinyi, 1981; Manzanilla, 2002a; 2002b; 2017a).

Un aspecto que reitera la excepcionalidad de la ciudad de Teotihuacan, además de la traza urbana y la sociedad multiétnica, es la presencia de dos formas de organización social: una corporativa en la base y cima de la sociedad, y otra competitiva en los barrios (Manzanilla, 2015; 2017a; véase Blanton et al., 1996). A diferencia del área maya, en la que las ciudades estaban encabezadas por un gobernante único, muy representado en estelas, dinteles, textos, vasijas y 
esculturas, en Teotihuacan no tenemos estas representaciones, hecho que nos sugiere una organización corporativa también en la cima, es decir, un consejo de gobierno.

La élite gobernante aparece como austera en el registro arqueológico. Sin embargo, el aspecto más dinámico de la sociedad teotihuacana yace en sus élites intermedias: los administradores de cada barrio, emprendedores, competitivos. $\mathrm{Y}$ estas características son precisamente las que entran en contradicción con el desiderátum corporativo de las élites gobernantes austeras. Y mi propuesta respecto del incendio de la porción central de la ciudad hacia 570 d.C. (SolerArechalde et al., 2006; Beramendi-Orosco et al., 2020; Millon, 1988: 149-152) es precisamente una revuelta de las élites intermedias contra los espacios de poder de las élites gobernantes (Manzanilla, 2003; 2015), probablemente frente a un intento tardío de control de la excesiva autonomía de los barrios.

\section{La caída de Teotihuacan}

El centro rector de la ciudad fue incendiado hacia 570 d.C. (Soler Arechalde et al., 2006; Beramendi Orosco et al., 2020), probablemente a raíz de una revuelta interna de las élites de los barrios y sus maestros artesanos contra la élite gobernante (Manzanilla, 2015). Existen trazas de fuego en la porción central de la ciudad, que, según Millon (1988: 149-152), afectó a todas las estructuras monumentales de la Calzada de los Muertos, además de los templos y construcciones asociadas del resto de la ciudad. De los 965 conjuntos de apartamentos examinados, sólo 45 mostraron evidencias claras de incendio (un 5\%). En general, el fuego se detectó en el frente, a los lados de las escalinatas y sobre las plataformas de los templos (Millon, 1988: 150), aunque en el centro de barrio de Teopancazco sólo vimos fuego intencional en el sector suroeste (Manzanilla, 2012d) hacia 575 d.C. (Soler Arechalde et al., 2006), sector en que probablemente moraban los administradores del barrio en Xolalpan tardío.

En el complejo palaciego de Xalla (véase Fig. 7), entre las pirámides del Sol y de la Luna (Manzanilla, 2008; 2017c; Manzanilla, 2019) hemos corroborado la destrucción por fuego muy intenso de la plaza central con las cuatro estructuras a los rumbos cardinales y el templo del centro, cuyos pisos quemados arrojaron fechamientos arqueomagnéticos alrededor del 570 d.C. (Beramendi Orosco et al., 2020; Soler Arechalde et al., 2006).

En los complejos arquitectónicos principales del núcleo de la ciudad, como el Palacio de Quetzalpapálotl (Acosta, 1964: 25), Xalla (Manzanilla, 2008; 2017c; Manzanilla, 2019), la Casa de los Sacerdotes (Batres, 1906: 15), el Grupo Viking (Armillas, 1944) y la Estructura 1D de La Ciudadela (Jarquín Pacheco y Martínez Vargas, 1982: 123), tenemos evidencias de vigas y morillos carbonizados sobre el último piso de ocupación teotihuacana.

Después del incendio y la destrucción de los escenarios de las élites gobernantes, muchos nobles se fueron de la ciudad hacia varios derroteros en Mesoamérica, junto con artesanos calificados y sirvientes. Además de la revuelta, que ocurre 
en un momento de particular vulnerabilidad de la ciudad, existe la sugerencia de una posible sequía prolongada (García, 1974), que afectó directamente el abasto de alimentos y agua, además de una degradación severa del ambiente del valle de Teotihuacan debido a la deforestación y sobreexplotación de acuíferos. Asimismo, hubo efectos dramáticos de la mancha urbana sobre su ambiente (particularmente la necesidad de combustible doméstico, artesanal y para la quema de cal, que produjo una tala considerable de la cubierta arbórea, como han sugerido Mooser (1968: 31) así como Barba y Córdova Frunz (1999), además de otros efectos como la erosión de suelos, nula recarga de acuíferos, azolve de presas derivadoras, decremento en el gasto de los manantiales, $y$, por ende, cosechas sin regularidad). Otros factores citados son la torpeza de la burocracia teotihuacana para tratar con grupos de diversos intereses, la mala administración de la economía y la inflexibilidad hacia el cambio (Millon, 1988: 149), además del probable bloqueo de las rutas de aprovisionamiento por el lado oriental (Chadwick, 1966: 2).

La fase Metepec (550-650 d.C.) vio la decadencia del sistema teotihuacano, patente en la mala calidad de las construcciones y el colapso del sistema de abasto; muchos más se fueron de la ciudad. Pronto llegarían del Bajío los saqueadores de la ciudad: los Coyotlatelco del Epiclásico; buscaban ofrendas fundacionales con jadeíta, vivieron en túneles alrededor de la Pirámide del Sol (Manzanilla et al., 1996), pero también en los espacios de la plataforma que circundaba por tres lados el templo principal de la ciudad. Eran pequeños grupos familiares, y nunca más se vería un gran asentamiento urbano en esta región.

\section{Consideraciones finales}

Dos ciudades emblemáticas -Uruk-Warka y Teotihuacan- dejaron un legado económico, social y simbólico en sus regiones, ya que fueron los primeros experimentos de vida urbana, de nuevas formas de interacción, de la aparición de oficios de tiempo completo que requerían una organización para el abasto de alimentos para la población no-productora de ellos.

El proceso de concentración de bienes y su ulterior redistribución explica cómo pudo una población heterogénea concentrarse en un espacio urbano en Mesopotamia; cada centro de redistribución organizó a varios individuos y familias en múltiples tareas. La posible exportación de estos módulos eficientes de articulación de la población rural por parte de la urbana, de un movimiento coordinado de bienes, y del abasto de las materias primas y bienes alóctonos por medio de redes de intercambio habla de un nuevo orden de relaciones.

En el centro de México, la gran ciudad ortogonal de Teotihuacan funcionó gracias a la dinámica de sus barrios y a las alianzas de éstos con sitios dispuestos en corredores hacia regiones ricas en materias primas y bienes suntuarios. El flujo de bienes y personas se logró gracias a la semi-autonomía de los barrios. Ambos ejemplos de ciudades prístinas exportaron sus formas eficientes de organización para abastecerse de materias primas, productos y trabajadores foráneos, a través de enclaves. 
En ambos casos se percibe una vena corporativa en sus sociedades: en UrukWarka, antes del surgimiento de los palacios, uno observa este tipo de organización en las redes redistributivas y de control de bienes en almacenes. En Teotihuacan, la organización corporativa yace en los grupos corporativos que habitan los conjuntos de departamentos, y posiblemente en un consejo de cogobernantes (Manzanilla, 2017a).

Sin embargo, existieron también diferencias profundas entre las dos ciudades. Una de ellas atañe a la articulación multiétnica de Teotihuacan, ya que la multietnicidad y el multilingüismo son características básicas de Mesoamérica, que contrastan con otras regiones. No deja de maravillarnos cómo lograron pactos de vida común con contingentes étnicos de diversos orígenes y bases lingüísticas.

Otra diferencia yace en la traza ortogonal de la ciudad de Teotihuacan, que no tiene paralelos en Mesopotamia, pero sí en las ciudades más importantes del valle del Indo, como Harappa y Mohenjo-Daro. Asimismo, podemos ver que estas ciudades comparten una vocación por la producción artesanal en talleres de diverso orden.

La importancia de la gran ciudad de Teotihuacan trascendió su tiempo. Para los pueblos que llegaron posteriormente a la cuenca de México, Teotihuacan fue oráculo sagrado, el lugar de nacimiento del quinto sol cosmogónico, sitio de creación de dioses y astros (véase León-Portilla, 1971), punto donde se recibía el poder para gobernar; quizás incluso la Tollan arquetípica (Manzanilla, 1997b), es decir, "la primera gran ciudad".

Con el colapso de Teotihuacan, hay una declinación constante del nivel demográfico y dispersión de la población (Parsons, 1974: 106). El reordenamiento de las esferas de poder, así como una "balcanización" tuvieron lugar, junto con el consecuente surgimiento de pequeñas unidades políticas de tipo "ciudadestado" (Marcus, 1989: 201): Cholula, Cacaxtla, Xochicalco y Tula en el altiplano central, y Tajín, en la costa del golfo de México. Predominan durante el Epiclásico estrategias de red al desintegrarse la base corporativa; el poder político estaba ligado al desempeño de estos sitios en las redes de intercambio a larga distancia de objetos de prestigio (Blanton et al., 1996: 10). 


\section{Q Bibliografía}

" Acosta, J. (1964). El palacio de Quetzalpapalotl. México: INAH.

»Adams, R. McC. (1960). The Origin of Cities, en: Scientific American, September (Reprint 606). San Francisco: W. H. Freeman and Co.

»Adams, R. McC. y Nissen, H. J. (1972). The Uruk Countryside. The Natural Settings of Urban Societies. Chicago: The University of Chicago Press.

»Álvarez Sandoval, B. A., Manzanilla, L. R., González-Ruiz, M., Malgosa, A. y Montiel, R. (2015). Genetic Evidence Supports the Multiethnic Character of Teopancazco, a Neighborhood Center of Teotihuacan, Mexico (AD 200-600), en: PLOS ONE 10 (7): 1-19.

"Armillas, P. (1944). Exploraciones recientes en Teotihuacan, México, en: Cuadernos americanos XVI (4): 121-136.

» Barba, L. y Córdova Frunz, J. L. (1999). Estudios energéticos de la producción de cal en tiempos teotihuacanos y sus implicaciones, en: Latin American Antiquity 10 (2): 168-179.

»Batres, L. (1906). Teotihuacan. Memoria. México: Imprenta de Fidencio S. Soria.

»Beramendi Orosco, L., González Hernández, G., Soler Arechalde, A. M. y Manzanilla, L. R. (2020). A high-resolution chronology for the palatial complex of Xalla in Teotihuacan, Mexico, combining radiocarbon ages and archaeomagnetic dates in a Bayesian model, en: Radiocarbon 130, DOI:10.1017/ RDC.2020.130, diciembre: 1-12.

» Blanton, R. E., Feinman, G. M., Kowalewski, S. A. y Peregrine, P. N. (1996). A Dual-Processual Theory for the Evolution of Mesoamerican Civilization, en: Current Anthropology 37: 1-14.

»Calvino, I. (2011). Las ciudades invisibles (21 ${ }^{a}$ edición, Biblioteca Calvino). Madrid: Ediciones Siruela.

"Carballo, D. M. (2011). Obsidian and the Teotihuacan State: Weaponry and Ritual Production at the Moon Pyramid. Pittsburgh-México: University of PittsburghInstituto de Investigaciones Antropológicas, Universidad Nacional Autónoma de México.

»Chadwick, R. E. L. (1966). The 'Olmeca-Xicallanca' of Teotihuacan: A Preliminary Study, en: Mesoamerican Notes 7-8: 1-24.

»Childe, V. G. (1957). Civilizations, Cities, and Towns, en: Antiquity XXXI (121): 36-38.

»Childe, V. G. (1964 [1951]). Evolución social (Problemas científicos y filosóficos 29). México: Universidad Nacional Autónoma de México.

»Childe, V. G. (1968 [1935]). Nacimiento de las civilizaciones orientales (Historia, Ciencia y Sociedad 31). Barcelona: Ediciones Península.

»Childe, V. G. (1971 [1936]). Los orígenes de la civilización (Breviarios 92). México: Fondo de Cultura Económica.

»Childe, V. G. (1973). The Urban Revolution, en: Leone, M. P. (ed.), Contemporary Archaeology. Carbondale: Southern Illinois University Press, 43-51. 
»De la Fuente, B. (ed.) (1996). La pintura mural prehispánica en México. I. Teotihuacan. México: Instituto de Investigaciones Estéticas, Universidad Nacional Autónoma de México.

»Doxiadis, C. A. (1968). Ekistics. An Introduction in the Science of Human Settlements. Londres: Hutchinson and Co.

»Drucker, P. (1943). Ceramic Stratigraphy at Cerro de las Mesas, Veracruz, Mexico (Bulletin 141). Washington D.C.: Smithsonian Institution.

》Espinosa, G. y Manzanilla, L. (1985). Consideraciones en torno a la capacidad de los cuencos troncocónicos de Arslantepé (Malatya), en: Quaderni de 'La ricerca scientifica' 112: 139-162.

" Fox, R. G. (1977). Urban Anthropology: Cities in Their Cultural Settings. Englewood Cliffs: Prentice-Hall.

» Frangipane, M. (2001). On Models and Data in Mesopotamia, en: Current Anthropology 42 (3): 415-416.

"Froese, T., Gershenson, C. y Manzanilla, L. R. (2014). Can government be selforganized? A mathematical model of the collective social organization of ancient Teotihuacan, Central Mexico, en: PLOS ONE 9 (10): e109966.

" García, E. (1974). Situaciones climáticas durante el auge y la caída de la cultura teotihuacana, en: Boletín 5, Instituto de Geografía de la Universidad Nacional Autónoma de México: 35-70.

»García Cook, Á. (1981). 8. The Historical Importance of Tlaxcala in the Cultural Development of the Central Highlands, en: Sabloff, J. A. (ed.), Supplement to the Handbook of Middle American Indians, Archaeology l. Austin: University of Texas Press, 244-276.

»Gazzola, J. (2005). La producción lapidaria en Teotihuacán, estudio de las actividades productivas en los talleres de un conjunto habitacional, en: Ruiz G., M. E. y Torres P., J. (eds.), Memoria de la Tercera Mesa Redonda de Teotihuacán, Arquitectura y Urbanismo: Pasado y presente de los espacios en Teotihuacán. México: INAH, 841-878.

"Gazzola, J. (2017). Reappraising Architectural Processes at the Ciudadela through Recent Evidence, en: Robb, M. H. (ed.), Teotihuacan: City of Water, City of Fire. San Francisco-Berkeley: Fine Arts Museums of San Francisco, in association with the University of California Press, 38-47.

» Gibson, McG. (1993). Nippur, sacred city of Enlil, en: Al-Rafidan XIV: 1-18.

»Gómez Chávez, S. (1998). Nuevos datos sobre la relación de Teotihuacan y el Occidente de México, en: Antropología e Historia del Occidente de México. XXIV Mesa Redonda de la Sociedad Mexicana de Antropología, vol. III. México: Sociedad Mexicana de Antropología-Universidad Nacional Autónoma de México, 1461-1493.

"Hardoy, J. E. (1964). Ciudades precolombinas (Biblioteca de Planeamiento y Vivienda 7). Buenos Aires: Ediciones Infinito.

»Hirth, K. G. (2003). The Altepetl and Urban Structure in Prehispanic Mesoamerica, en: Sanders, W. T., Mastache, A. G. y Cobean, R. H. (eds.), El urbanismo en Mesoamérica, vol. I. México: Instituto Nacional de Antropología e Historia-The Pennsylvania State University, 57-84.

»Hole, F. (1974). Investigating the Origins of Mesopotamian Civilization, en: Lamberg-Karlovsky, C. C. y Sabloff, J. A. (eds.), The Rise and Fall of Civilizations 
(Modern Archaeological Approaches to Ancient Cultures). Menlo Park: Cummings Publishing Company, 269-281.

"Hourani, A. H. (1970). Introduction: The Islamic City in the Light of Recent Research, en: Hourani, A. H. y Stern, S. M. (eds.), The Islamic City. A Colloquium. Filadelfia: University of Pennsylvania Press, 9-24.

"Jarquín Pacheco, A. M. y Martínez Vargas, E. (1982). 5. Las excavaciones en el Conjunto 1D, en: Cabrera Castro, R., Rodríguez G., I. y Morelos G., N. (eds.), Memoria del Proyecto Arqueológico Teotihuacan 80-82. México: Instituto Nacional de Antropología e Historia, 89-126.

"León-Portilla, M. (1971). De Teotihuacan a los Aztecas. Antología de fuentes e interpretaciones históricas. México: Instituto de Investigaciones Históricas, Universidad Nacional Autónoma de México.

»Linné, S. (1934). Archeological Researches at Teotihuacan, Mexico. Estocolmo: Ethnographical Museum of Sweden.

"Linné, S. (1942). Mexican Highland Cultures. Archaeological Researches at Teotihuacan, Calpulalpan and Chalchicomula in 1934-35. Estocolmo: Ethnographical Museum of Sweden.

"López-Austin, A. (1989). 1. La historia de Teotihuacan, en: López-Austin, A., Romero Galván, J. R. y Martínez Marín, C. (eds.), Teotihuacan. México: El Equilibrista, Citicorp/Citibank, 13-35.

" López-Puértolas, C., Manzanilla-Naim, L. R. y Vázquez-de-Ágredos-Pascual, M. L. (2020). Characterization of color production in the Xalla's palace complex, Teotihuacan, en: STAR: Science and Technology of Archaeological Research (YSTA 1723240) 6 (1), DOI: 10.1080/20548923.2020.1723240, 1-14.

》Lorenzo, J. L. (1968). Materiales para la arqueología de Teotihuacan. México: Instituto Nacional de Antropología e Historia.

"Manzanilla, L. R. (1983). La redistribución como proceso de centralización de la producción y circulación de bienes. Análisis de dos casos, en: Boletín de Antropología Americana 7: 5-18.

"Manzanilla, L. R. (1985a). Templo y palacio: proposiciones sobre el surgimiento de la sociedad urbana y el Estado, en: Anales de Antropología 22: 91-114.

"Manzanilla, L. R. (1985b). El sitio de Cuanalan en el marco de las comunidades pre-urbanas del Valle de Teotihuacan, en: Monjarás-Ruiz, J., Pérez Rocha, E. y Brambila, R. (eds.), Mesoamérica y el centro de México (Colección Biblioteca del INAH). México: Instituto Nacional de Antropología e Historia, 133-178.

"Manzanilla, L. R. (1986). La constitución de la sociedad urbana en Mesopotamia (Serie Antropológica 80). México: Instituto de Investigaciones Antropológicas, Universidad Nacional Autónoma de México.

»Manzanilla, L. R. (1992). The Economic Organization of the Teotihuacan Priesthood: Hypotheses and Considerations, en: Berlo, J. C. (ed.), Art, Ideology, and the City of Teotihuacan. Washington D.C.: Dumbarton Oaks Research Library and Collections, 321-338.

" Manzanilla, L. R. (ed.) (1993). Anatomía de un conjunto residencial teotihuacano en Oztoyahualco, 2 vols. México: Instituto de Investigaciones Antropológicas, Universidad Nacional Autónoma de México.

"Manzanilla, L. R. (1996). Corporate Groups and Domestic Activities at Teotihuacan, en: Latin American Antiquity 7 (3): 228-246. 
»Manzanilla, L. R. (1997a). Chapter 1. Early Urban Societies: Challenges and Perspectives, en: Manzanilla, L. (ed.), Emergence and Change in Early Urban Societies (Plenum Series in Fundamental Issues in Archaeology). Nueva York: Plenum Press, 3-39.

»Manzanilla, L. R. (1997b). Chapter 5. Teotihuacan: Urban Archetype, Cosmic Model, en: Manzanilla, L. (ed.), Emergence and Change in Early Urban Societies (Plenum Series in Fundamental Issues in Archaeology). Nueva York: Plenum Press, 109-132.

"Manzanilla, L. R. (2001). La zona del Altiplano central en el Clásico, en: Manzanilla, L. y López-Luján, L. (eds.), Historia antigua de México, vol. II. México: Miguel Ángel Porrúa editor-Instituto Nacional de Antropología e HistoriaUniversidad Nacional Autónoma de México, 203-239.

"Manzanilla, L. R. (2002a). Organización sociopolítica de Teotihuacan: lo que los materiales arqueológicos nos dicen o nos callan, en: Memorias de la Primera Mesa Redonda de Teotihuacan. México: UNAM-INAH, 3-21.

"Manzanilla, L. R. (2002b). Gobierno corporativo en Teotihuacan: una revisión del concepto 'palacio' aplicado a la gran urbe prehispánica, en: Anales de Antropología 35: 157-190.

» Manzanilla, L. R. (2003). 7. The Abandonment of Teotihuacan, en: Inomata, T. y Webb, R. W. (eds.). The Archaeology of Settlement Abandonment in Middle America (Foundations of Archaeological Inquiry). Salt Lake City: The University of Utah Press, 91-101.

» Manzanilla, L. R. (2006a). Estados corporativos arcaicos. Organizaciones de excepción en escenarios excluyentes, en: Revista Cuicuilco 13 (36): 13-45.

» Manzanilla, L. R. (2006b). La producción artesanal en Mesoamérica, en: Arqueología Mexicana XIV (80) (julio-agosto): 28-35.

"Manzanilla, L. R. (2007a). Las “casas” nobles de los barrios de Teotihuacan: estructuras exclusionistas en un entorno corporativo, en: Memoria $2007 \mathrm{de} \mathrm{El}$ Colegio Nacional. México: El Colegio Nacional, 453-470.

"Manzanilla, L. R. (2007b). La unidad doméstica y las unidades de producción. Propuesta interdisciplinaria de estudio, en: Memoria 2007 de El Colegio Nacional. México: El Colegio Nacional, 415-451.

" Manzanilla, L. R. (2008). La iconografía del poder en Teotihuacan, en: Olivier, G. (ed.), Símbolos de poder en Mesoamérica. México: Instituto de Investigaciones Históricas e Instituto de Investigaciones Antropológicas, Universidad Nacional Autónoma de México, 111-131.

» Manzanilla, L. R. (2009). Corporate Life in Apartment and Barrio Compounds at Teotihuacan, Central Mexico: Craft Specialization, Hierarchy and Ethnicity, en: Manzanilla, L. R. y Chapdelaine, C. (eds.), Domestic Life in Prehispanic Capitals: A Study of Specialization, Hierarchy and Ethnicity. Ann Arbor: University of Michigan, 21-42.

»Manzanilla, L. R. (2011a). Sistemas de control de mano de obra y del intercambio de bienes suntuarios en el corredor teotihuacano hacia la costa del Golfo en el Clásico, en: Anales de Antropología 45: 9-32.

» Manzanilla, L. R. (2011b). Metrópolis prehispánicas e impacto ambiental: el caso de Teotihuacan a través del tiempo, en: Caballero, M. y Ortega, B. (eds.), Escenarios de cambio climático, vol. 1, Registros del Cuaternario en América Latina. México: Fomento Editorial, Universidad Nacional Autónoma de México, 287-319. 
» Manzanilla, L. R. (2012a). Introducción. Teopancazco, un centro de barrio multiétnico de Teotihuacan, en: Manzanilla, L. R. (ed.), Estudios arqueométricos del centro de barrio de Teopancazco en Teotihuacan. México: Coordinación de Humanidades-Coordinación de la Investigación Científica, Universidad Nacional Autónoma de México, 17-66.

"Manzanilla, L. R. (2012b). Banco de datos del sitio Teopancazco. Proyecto “Teotihuacan: Elite y gobierno," 1997-2005, Apéndice 1, en: Manzanilla, L. R. (ed.). Estudios arqueométricos del centro de barrio de Teopancazco en Teotihuacan. México: Coordinación de Humanidades-Coordinación de la Investigación Científica, Universidad Nacional Autónoma de México, 467-552.

"Manzanilla, L. R. (2012c). Neighborhoods and Elite "Houses" at Teotihuacan, Central Mexico, en: Arnauld, M.-C., Manzanilla, L. R. y Smith, M. (eds.), The Neighborhood as a Social and Spatial Unit in Mesoamerican Cities. Tucson: University of Arizona Press, 55-73.

»Manzanilla, L. R. (ed.) (2012d). Estudios arqueométricos del centro de barrio de Teopancazco en Teotihuacan. México: Coordinación de HumanidadesCoordinación de la Investigación Científica, Universidad Nacional Autónoma de México.

»Manzanilla, L. R. (2015). Cooperation and Tensions in Multiethnic Corporate Societies Using Teotihuacan, Central Mexico, as a Case Study, en: Proceedings of the National Academy of Sciences 112 (30): 9210-9215.

»Manzanilla, L. R. (2017a). Teotihuacan, ciudad excepcional de Mesoamérica (Colección Opúsculos). México: El Colegio Nacional.

»Manzanilla, L. R. (2017b). Discussion. The Subsistence of the Teotihuacan Metropolis, en: Archaeological and Anthropological Sciences 9 (1): 133-140.

»Manzanilla, L. R. (2017c). The Xalla palace in Teotihuacan, en: Robb, M. H. (ed.), Teotihuacan. City of Water, City of Fire. San Francisco: Fine Arts Museums of San Francisco-De Young and University of California Press, 118-123.

"Manzanilla, L. R. (ed.) (2017d). Multiethnicity and Migration at Teopancazco. Investigations of a Teotihuacan Neighborhood Center. Gainesville: University Press of Florida.

»Manzanilla, L. R. (ed.) y Valadez, R. (coord.) (2017e). El uso de los recursos naturales en un centro de barrio de Teotihuacan: Teopancazco. México: Instituto de Investigaciones Antropológicas-Dirección General de Asuntos del Personal Académico, Universidad Nacional Autónoma de México.

"Manzanilla, L. R. (2018a). Corporate societies with exclusionary social components: the Teotihuacan metropolis, en: Frangipane, M. y Manzanilla, L. R. (eds.), Origini. Prehistory and Protohistory of Ancient Civilizations. Thematic Issue. In memory of Robert McC. Adams XLII, 2018-2. Roma: "Sapienza" Università di Roma, 211-225.

»Manzanilla, L. R. (ed.) (2018b). Teopancazco como centro de barrio multiétnico de Teotihuacan. Los sectores funcionales y el intercambio a larga distancia. México: Dirección General de Asuntos del Personal Académico-Instituto de Investigaciones Antropológicas, Universidad Nacional Autónoma de México.

" Manzanilla, L. R. (ed.) (2019). El palacio de Xalla en Teotihuacan. Primer acercamiento. México: Dirección General de Asuntos del Personal AcadémicoInstituto de Investigaciones Antropológicas, Universidad Nacional Autónoma de México. 
»Manzanilla, L. R. (ed.) (2020) La población de Teopancazco, un centro de barrio multiétnico de Teotihuacan. México: Dirección General de Asuntos del Personal Académico-Instituto de Investigaciones Antropológicas de la Universidad Nacional Autónoma de México.

» Manzanilla, L., López, C. y Freter, A.-C. (1996). Dating Results from Excavations in Quarry Tunnels behind the Pyramid of the Sun at Teotihuacan, en: Ancient Mesoamerica 7: 245-266.

» Manzanilla, L. R., Bokhimi, X., Tenorio, D., Jiménez, M., Rosales, E., Martínez, C. y Winter, M. (2017). Procedencia de la mica de Teotihuacan. Control de los recursos suntuarios foráneos por las élites gobernantes, en: Anales de Antropología 51: 23-38.

» Marcus, J. (1983). On the Nature of the Mesoamerican City, en: Vogt, E. Z. y Leventhal, R. M. (eds.), Prehistoric Settlement Patterns. Essays in Honor of Gordon R. Willey. Cambridge: University of New Mexico Press and Peabody Museum of Archaeology and Ethnology, 195-242.

" Marcus, J. (1989). From Centralized Systems to City-States: Possible Models for the Epiclassic, en: Diehl, R. A. y Berlo, J. C. (eds.), Mesoamerica after the Decline of Teotihuacan, A.D. 700-900, Washington D.C.: Dumbarton Oaks Research Library and Collection, 201-208.

"McClung, E. (1979). Plants and Subsistence in the Teotihuacan Valley A.D. 100750, Tesis doctoral de Antropología, Brandeis University. Ann Arbor: University Microfilms.

» Millon, R. (1973). Urbanization at Teotihuacan, Mexico. Volume I: The Teotihuacan Map. Austin: University of Texas Press.

» Millon, R. (1988). The Last Years of Teotihuacan Dominance, en: Yoffee, N. y Cowgill, G. L. (eds.), The Collapse of Ancient States and Civilizations. Tucson: The University of Arizona Press, 102-164.

»Mooser, F. (1968). Geología, naturaleza y desarrollo del Valle de Teotihuacan, en: Lorenzo, J. L. (ed.), Materiales para la arqueología de Teotihuacan. México: Instituto Nacional de Antropología e Historia, 29-37.

» Mumford, L. (1970). The Natural History of Urbanization, en: Thomas Jr., W. L. (ed.), Man's Role in Changing the Face of the Earth, vol. I. Chicago: The University of Chicago Press, 382-398.

» Múnera, C. (1985). Un taller de cerámica ritual en la Ciudadela (Tesis de licenciatura en Arqueología). México: Escuela Nacional de Antropología e Historia.

» Nissen, H. J. (2018). The city of Uruk and its Hinterland, en: Frangipane, M. y Manzanilla, L R. (eds.), Origini. Prehistory and Protohistory of Ancient Civilizations. Thematic Issue. In memory of Robert McC. Adams XLII, 2018-2. Roma: "Sapienza" Università di Roma, Gangemi Editore International, 61-71.

"Ortega Cabrera, V. (2014). La presencia oaxaqueña en Teotihuacán durante el Clásico (Tesis de doctorado). México: Facultad de Filosofía y Letras, Universidad Nacional Autónoma de México.

"Palmieri, A. (1973). Scavi nell'area sud-occidentale di Arslantepe, en: Origini 7: 55-228.

»Parsons, J. R. (1974). The Development of a Prehistoric Complex Society: A Regional Perspective from the Valley of Mexico, en: Journal of Field Archaeology I (1-2): 81-108. 
»Paulinyi, Z. (1981). Capitals in Pre-Aztec Central Mexico, en: Acta Orientalia Academiae Scientiarum Hungarica XXXV (2-3): 315-250.

»Plunket, P. y Uruñuela, G. (1998). Preclassic Household Patterns preserved under Volcanic Ash at Tetimpa, Puebla, Mexico, en: Latin American Antiquity 9 (4): 287-309.

"Pollock, S. (1999). Ancient Mesopotamia. The Eden that Never Was. Cambridge: Cambridge University Press.

»Price, T. D., Manzanilla, L. y Middleton, W. H. (2000). Immigration and the Ancient City of Teotihuacan in Mexico: A Study Using Strontium Isotope Ratios in Human Bone and Teeth, en: Journal of Archaeological Science 27: 903-913.

»Rattray, E. C. (1988). Nuevas interpretaciones en torno al Barrio de los Comerciantes, en: Anales de Antropología XXV: 165-180.

»Rattray, E. C. (1989). El Barrio de los Comerciantes y el conjunto de Tlamimilolpa: un estudio comparativo, en: Arqueología 5: 105-129.

»Rodríguez Galicia, B. y Valadez Azúa, R. (2013). Vestigios del recurso costero en el sitio arqueológico de Teopancazco, Teotihuacan, Estado de México, en: Revista Española de Antropología Americana 43 (1): 9-29.

»Rosales de la Rosa, E. y Manzanilla, L. R. (2011). Producción, consumo y distribución de la mica en Teotihuacan. Presencia de un recurso alóctono en los contextos arqueológicos de dos conjuntos arquitectónicos: Xalla y Teopancazco, en: Manzanilla, L. R. y Hirth, K. (eds.), La producción artesanal y especializada en Mesoamérica. Áreas de actividad y procesos productivos, México: Instituto Nacional de Antropología e Historia-Universidad Nacional Autónoma de México, 131-152.

»Sanders, W. T. (1967). Settlement Patterns, en: Wauchope, R. (ed.), Handbook of Middle American Indians, vol. VI. Austin: University of Texas Press, 53-86.

»Sanders, W. T. (1968a). A Profile of Urban Evolution in the Teotihuacan Valley, en: Actas y Memorias del XXXVII Congreso Internacional de Americanistas, vol. 1. Buenos Aires: Departamento de Publicaciones Científicas, 95-103.

»Sanders, W. T. (1968b). Hydraulic Agriculture, Economic Symbiosis, and the Evolution of States in Central Mexico, en: Anthropological Archaeology in the Americas. Washington: The Anthropological Association of Washington, 88-107.

"Sanders, W. T., Parsons, J. R. y Santley, R. S. (1979). The Basin of Mexico. Ecological Processes in the Evolution of a Civilization (Studies in Archaeology). Nueva York: Academic Press.

"Séjourné, L. (1959). Un palacio en la Ciudad de los Dioses. México: Instituto Nacional de Antropología e Historia.

»Séjourné, L. (1966). Arquitectura y pintura de Teotihuacan. México: Siglo XXI Editores.

» Sjoberg, G. (1960). The Preindustrial City: Past and Present. Glencoe: The Free Press.

»Soler Arechalde, A. M., Sánchez, F., Rodríguez, M., Caballero Miranda, M., Goguitchaishvili, A., Urrutia-Fucugauchi, J., Manzanilla, L. y Tarling, D. (2006). Archaeomagnetic investigations of some oriented pre-Columbian lime plasters from Teotihuacan, Mesoamerica, en: Earth, Planets and Space 58 (10): 1433-1439.

» Spence, M. W. (1992). Tlailotlacan, a Zapotec Enclave in Teotihuacan, en: Berlo, 
J. C. (ed.). Art, Ideology, and the City of Teotihuacan. Washington D.C.: Dumbarton Oaks Research Library and Collections, 59-88.

»Starbuck, D. R. (1975). Man-Animal Relationships in Pre-Columbian Central Mexico (Tesis doctoral). New Haven: Department of Anthropology, Yale University.

"Stein, G. J. y Özbal, R. (2007). A Tale of Two Oikumenai: Variation in the Expansionary Dynamics of 'Ubaid and Uruk Mesopotamia, en: Stone, E. C. (ed.), Settlement and Society. Essays Dedicated to Robert McCormick Adams. Los Ángeles-Chicago: Cotsen Institute of Archaeology, University of California, Los Angeles-The Oriental Institute, The University of Chicago, 329-342.

"Storey, R. y Widmer, R. J. (1989). Household and Community Structure of a Teotihuacan Apartment Compound: $\mathrm{S}_{3} \mathrm{~W}_{1}: 33$ of the Tlajinga Barrio, en: MacEachern, S., Archer, D. J. W. y Garvin, R. D. (eds.), Households and Communities. Calgary: The Archaeological Association of the University of Calgary, Chacmool, 407-415.

» Sugiyama, N., Sugiyama, S., Ortega, V. y Fash, W. (2016). ¿Artistas mayas en Teotihuacan?, en: Arqueología Mexicana 142: 8.

"Taube, K. (2003). Tetitla and the Maya Presence at Teotihuacan, en: Braswell, G. E. (ed.), Teotihuacan and the Maya. Reinterpreting Early Classic Maya Interaction. Austin: University of Texas Press, 274-314.

》 Trigger, B. (1972). Determinants of Urban Growth in Pre-Industrial Societies, en: Ucko, P. J., Tringham, R. y Dimbleby, G. W. (eds.), Man, Settlement, and Urbanism. Hertfordshire: Gerald Duckworth and Co., 575-598.

" Turner, M. (1992). Style in Lapidary Technology: Identifying the Teotihuacan Lapidary Industry, en: Berlo, B. (ed.), Art, Ideology and the City of Teotihuacan. Washington D.C.: Dumbarton Oaks, 89-112.

»Valadez, R. (1993). Capítulo 15. Macrofósiles faunísticos, en: Manzanilla, L. (ed.), Anatomía de un conjunto residencial teotihuacano en Oztoyahualco, v. 2. México: Instituto de Investigaciones Antropológicas, Universidad Nacional Autónoma de México, 729-831.

"Wheatley, P. (1971). The Pivot of the Four Quarters. A Preliminary Enquiry into the Origins and Character of the Ancient Chinese City. Chicago: Aldine Publishing Co.

»Wolf, E. R. (1976). The Valley of Mexico, Studies in Pre-Hispanic Ecology and Society. Albuquerque: University of New Mexico Press. 
